\title{
Study on the Size-Dependent Oxidation Reaction Kinetics of Nanosized Zinc Sulfide
}

\author{
Qing-Shan Fu, Yong-Qiang Xue, Zi-Xiang Cui, and Ming-Fang Wang \\ Department of Applied Chemistry, Taiyuan University of Technology, Taiyuan 030024, China \\ Correspondence should be addressed to Yong-Qiang Xue; xyqlw@126.com
}

Received 6 May 2014; Revised 16 July 2014; Accepted 24 July 2014; Published 26 August 2014

Academic Editor: Zhongkui Hong

Copyright (C) 2014 Qing-Shan Fu et al. This is an open access article distributed under the Creative Commons Attribution License, which permits unrestricted use, distribution, and reproduction in any medium, provided the original work is properly cited.

\begin{abstract}
Numerous oxidation problems of nanoparticles are often involved during the preparation and application of nanomaterials. The oxidation rate of nanomaterials is much faster than bulk materials due to nanoeffect. Nanosized zinc sulfide (nano-ZnS) and oxygen were chosen as a reaction system. The influence regularities were discussed and the influence essence was elucidated theoretically. The results indicate that the particle size can remarkably influence the oxidation reaction kinetics. The rate constant and the reaction order increase, while the apparent activation energy and the preexponential factor decrease with the decreasing particle size. Furthermore, the logarithm of rate constant, the apparent activation energy and the logarithm of preexponential factor are linearly related to the reciprocal of particle diameter, respectively. The essence is that the rate constant is influenced by the combined effect of molar surface energy and molar surface entropy, the reaction order by the molar surface area, the apparent activation energy, by the molar surface energy, and the preexponential factor by the molar surface entropy. The influence regularities and essence can provide theoretical guidance to solve the oxidation problems involved in the process of preparation and application of nanomaterials.
\end{abstract}

\section{Introduction}

Because of nanoeffect, nanomaterials have great many peculiar physical and chemical properties [1-4]. Nano-ZnS presents plentiful excellent properties due to its nanostructural effects $[5,6]$. At present, nano-ZnS has been widely applied in various fields, such as luminescent materials, sensors, photocatalysis, and semiconductors [7-10]. However, nano-ZnS is oxidized easily in the process of preparation and application, and the oxidation rate is much faster than that with massive $\mathrm{ZnS}$. In fact, there is the possibility of being oxidized for most nanomaterials, causing the degradation of performance. The influence mainly depends on the rate of being oxidized. Therefore, it is vitally important to study the oxidation reaction kinetics of nanomaterials for their preparation and application.

The research related to oxidation kinetics of nano-ZnS has not been reported so far, and there are a few researches in particle size effect on oxidation kinetics of other nanoparticles. The results show that with the decrease of particle diameter, the rate constant increases [11] and the apparent activation energy and the preexponential factor decrease [1114]. What they have done lays a foundation for the continuing research of the oxidation reaction kinetics of nanoparticles. However, the particle size effect on the reaction order has not been considered and the essence of particle size effect on the oxidation reaction kinetics is unclear as well.

In this paper, by choosing nano-ZnS with different particle sizes and oxygen as the reaction system, the kinetic parameters of the oxidation reaction at different temperatures were determined and the regularities of particle size effect on the reaction kinetics were summarized. The essence of particle size effect on the oxidation reaction kinetics was also discussed theoretically.

\section{Experimental}

2.1. Preparation and Characterization of Nano- $\mathrm{ZnS}$. A certain amount of sodium hyposulfite $\left(\mathrm{Na}_{2} \mathrm{~S}_{2} \mathrm{O}_{3} \cdot 5 \mathrm{H}_{2} \mathrm{O}\right)$ and zinc acetate $\left(\left(\mathrm{CH}_{3} \mathrm{COO}\right)_{2} \mathrm{Zn} \cdot 2 \mathrm{H}_{2} \mathrm{O}\right)$ were dissolved in distilled water. The solution, whose $\mathrm{pH}$ value was adjusted by acetic acid and sodium dodecyl benzene sulfonate, used as surface 


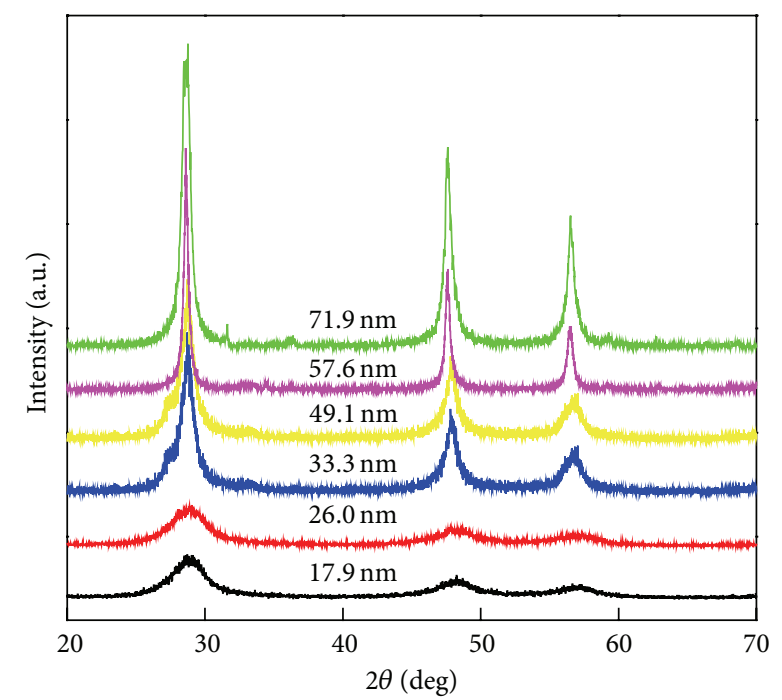

FIGURE 1: The XRD spectra for nano-ZnS with different diameters.

active agent, was added into a boiling flask-3-neck $(500 \mathrm{~mL})$ followed by heating and stirring. When the reaction was finished, after sucking filtration, after being washed by distilled water and absolute ethyl alcohol, and after being dried in a vacuum drying box, the nano-ZnS particles were obtained. The nano- $\mathrm{ZnS}$ with different sizes were obtained by changing the reaction temperature, initial $\mathrm{pH}$ value, heating method, and the kind of surface active agent which are shown in Table 1.

The XRD diffraction spectrum of nano- $\mathrm{ZnS}$ was determined by XRD-6000 ( $\mathrm{Cu} \mathrm{K} \alpha, \lambda=0.154178 \mathrm{~nm})$. The average particle diameter of nano-ZnS was calculated by Scherrer formula through the FWHMs of the diffraction peaks. The average particle diameters of nano-ZnS used in this experiment were 17.9, 26.0, 33.3, 49.1, 57.6, and $71.9 \mathrm{~nm}$, respectively. The XRD spectra are shown in Figure 1.

2.2. Reactions of Nano-ZnS. The reactions were performed in an autoclave (WDF-0.25, $250 \mathrm{~mL}$ ). Excessive nano-ZnS particles of a certain size were added into the autoclave and then oxygen was introduced slowly to drain the air out of the reactor, introducing about $0.20 \mathrm{MPa}$ oxygen into the reaction kettle again and then closing the inlet. The reaction equation is shown below:

$$
2 \mathrm{ZnS}(\mathrm{s})+3 \mathrm{O}_{2}(\mathrm{~g})=2 \mathrm{ZnO}(\mathrm{s})+2 \mathrm{SO}_{2}(\mathrm{~g}) .
$$

The reaction time and the corresponding pressure $( \pm 0.0001 \mathrm{MPa})$ were recorded when the temperature reached the target value by stirring in high speed.

2.3. Processing of Experimental Data. According to the total pressure, the mole fractions $\left(y_{\mathrm{O}_{2}}, y_{\mathrm{SO}_{2}}\right)$, the partial pressure $\left(p_{\mathrm{O}_{2}}, p_{\mathrm{SO}_{2}}\right)$, and mole numbers $\left(n_{\mathrm{O}_{2}}, n_{\mathrm{SO}_{2}}\right)$ at moment $t$ were calculated by the RK equation. Assuming that the reaction has a reaction order, the differential rate equation is expressed as follows:

$$
r=-\frac{d p_{\mathrm{O}_{2}}}{d t}=k p_{\mathrm{O}_{2}}^{\alpha} p_{\mathrm{SO}_{2}}^{\beta},
$$

where $r$ is the reaction rate, $t$ is the reaction time, $k$ is the rate constant, and $\alpha$ and $\beta$ are the partial reaction orders.

The reaction rate can be calculated approximately as follows:

$$
r=-\frac{d p_{\mathrm{O}_{2}}}{d t} \approx-\frac{\Delta p_{\mathrm{O}_{2}}}{\Delta t} .
$$

The logarithm form of (2) is as follows:

$$
\ln r=\ln k+\alpha \ln p_{\mathrm{O}_{2}}+\beta \ln p_{\mathrm{SO}_{2}} .
$$

According to (4), the partial reaction orders $\alpha$ and $\beta$ and the rate constant $k$ are calculated through multiple linear regression. If the correlation coefficient is close to 1 , the reaction has a reaction order and the total reaction order is $n=\alpha+\beta$.

The Arrhenius equation:

$$
\ln k=\ln A-\frac{E_{\mathrm{a}}}{R T},
$$

where $A$ is the preexponential factor, $E_{\mathrm{a}}$ is the apparent activation energy, and $T$ is the reaction temperature.

If the reaction follows the Arrhenius equation, the plot of logarithm of rate constant $\ln k$ against the reciprocal of temperature $1 / T$ should be a line; then $E_{\mathrm{a}}$ can be gotten from the slope and $A$ can be gotten from the intercept of this line. If the plot is not a line, the reaction is a non-Arrhenius reaction.

\section{Results and Discussion}

3.1. Effect of Particle Size on Rate Constant and Reaction Order. The reaction has a reaction order because the correlation coefficient is very close to $1(R>0.95)$. By combining $(3)$ and (4) with $p_{\mathrm{O}_{2}}$ and $p_{\mathrm{SO}_{2}}$ calculated by the RK equation, the $r$, $\alpha, \beta$, and $k$ are calculated. The logarithms of rate constants and reaction orders with different particle sizes of nano-ZnS at different temperatures are given in Tables 2 and 3.

At different temperatures, the curves of the logarithms of rate constants against the reciprocal of the particle diameters are shown in Figure 2.

It can be seen from Figure 2 that the particle size of nano$\mathrm{ZnS}$ has a marked influence on the reaction rate constant; the reaction rate constant increases when the particle size decreases and it is consistent with the reported results of reaction of nanoparticles in solutions [15-17]. At different temperatures, the logarithm of rate constant exhibits a linear relationship with the reciprocal of the particle diameter; the influence regularity is consistent with the result of reaction of nanoparticles in solution [15]. The theoretical relationship between the reaction rate constant and the reciprocal of particle diameter will be discussed below.

At different temperatures, the curves of the reaction orders versus the particle diameters are shown in Figure 3. 
TABLE 1: The average diameters of nano-ZnS prepared under different conditions.

\begin{tabular}{|c|c|c|c|c|c|}
\hline No. & Reaction temperature $/{ }^{\circ} \mathrm{C}$ & Initial $\mathrm{pH}$ value & Heating method & Surface active agent & Size/nm \\
\hline 1 & 90 & 4 & Persistent overheating & SDBS $^{* 1}$ & 17.9 \\
\hline 2 & 90 & 5 & Persistent overheating & CTMAB $^{* 2}$ & 26.0 \\
\hline 3 & 80 & 5 & Persistent overheating & SDBS & 33.3 \\
\hline 4 & 90 & 6 & Persistent overheating & SDBS & 49.1 \\
\hline 5 & 70 & 5 & Persistent overheating & SDBS & 57.6 \\
\hline 6 & $40-80-90$ & 5 & Temperature-gradient method & SDBS & 71.9 \\
\hline
\end{tabular}

${ }^{* 1}$ SDBS is sodium dodecyl benzene sulfonate.

${ }^{* 2}$ CTMAB is hexadecyl trimethyl ammonium bromide.

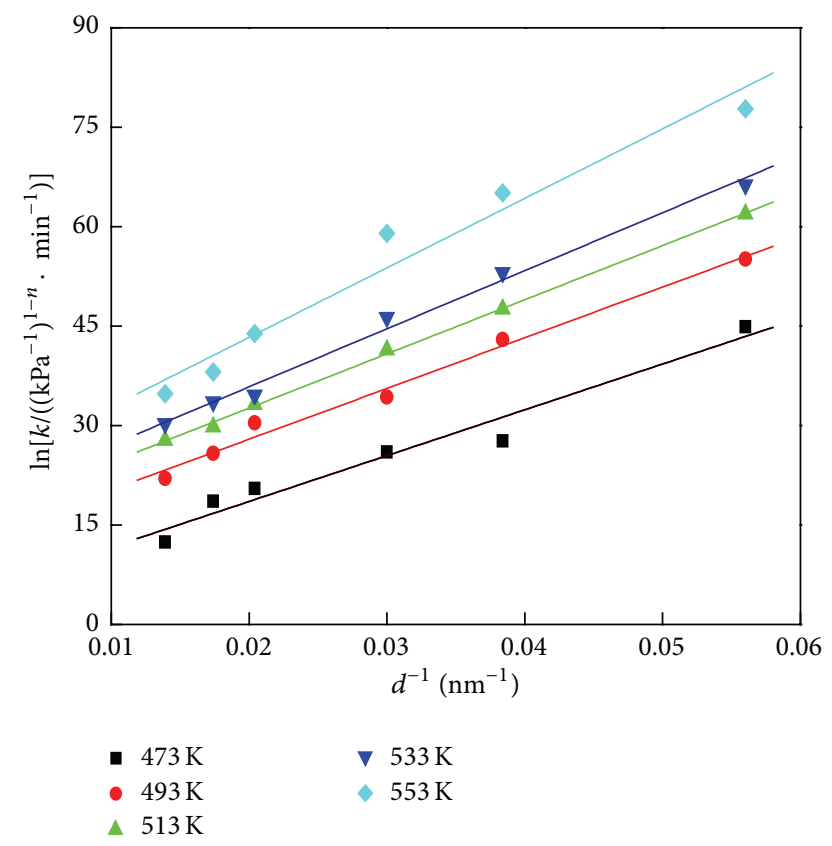

Figure 2: The curves of logarithms of rate constants versus the reciprocals of particle diameters.

As can be seen from Figure 3, there is a great influence of particle size of nano- $\mathrm{ZnS}$ on the reaction order. At the same temperature, the reaction order increases with the decrease of particle size; the influence regularity is consistent with the result of the reduction reaction of the nanoparticles [18] and is consistent with the result of reaction of nanoparticles in solutions [15-17]. The reaction order increases with the rising of temperature when the particle size remains unchanged. But with the particle size decreasing, the effect of temperature on the reaction order becomes smaller. For multiphase reaction, reducing the size of reactants can increase the specific surface area, thus speeding up the reaction rate; but solid particles in the reaction do not appear in the rate equation and thus the contribution of reducing particle size to accelerate the reaction rate is reflected in the effect of the partial pressure of oxygen on the reaction rate. Therefore, the increase of reaction order can attribute to the increase of molar surface area.

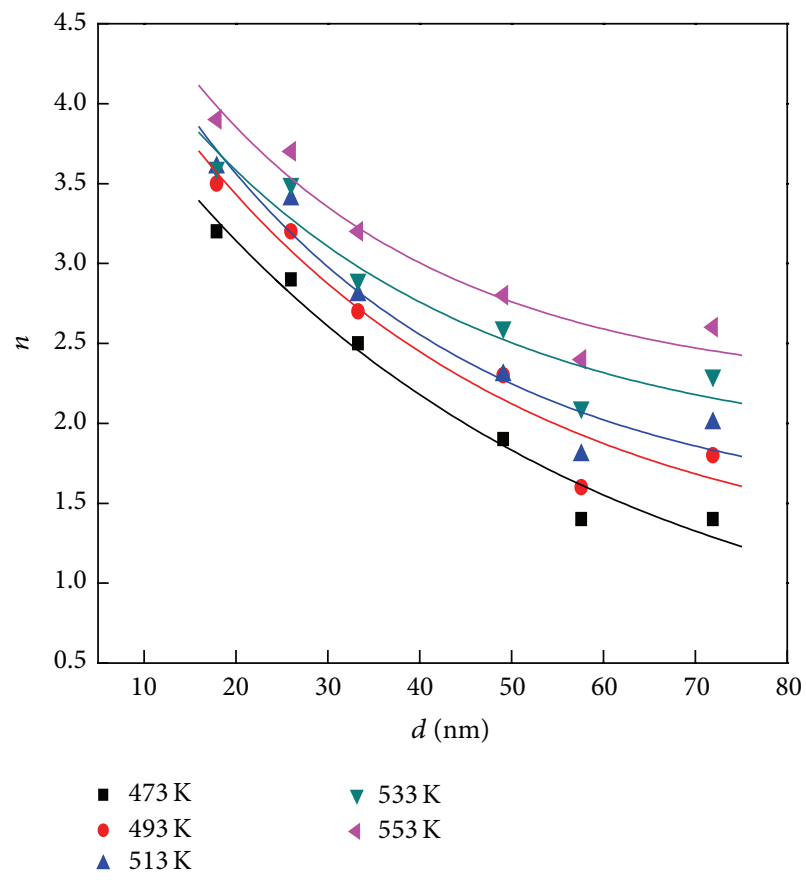

Figure 3: The curves of reaction orders versus particle diameters at different temperatures.

\subsection{Effect of Particle Size on Apparent Activation Energy} and Preexponential Factor. The curves of $\ln k$ versus $1 / T$ for nano-ZnS with different particle sizes are presented in Figure 4. As shown in Figure 4, $\ln k$ is proportional linearly to $1 / T$, which shows that the reaction of nano- $\mathrm{ZnS}$ with oxygen follows the Arrhenius formula. According to Arrhenius equation, the $\ln A$ and $E_{\mathrm{a}}$ for a given particle diameter can be obtained from the slope and intercept of the line, respectively (see Table 4).

From the data in Table 4, the curves of the apparent activation energies versus the reciprocals of the particle diameters are shown in Figure 5.

As shown in Figure 5, the particle size of nano- $\mathrm{ZnS}$ has a remarkable influence on the apparent activation energy. The apparent activation energy decreases with the decrease of particle size, which is consistent with the results of the reaction of the nanoparticles in solutions [15-17], the thermal decomposition reactions of the nanoparticles [19$22]$, and the reduction reactions of the nanoparticles [18, 
TABLE 2: The logarithms of the rate constants for different particle diameters at different temperatures.

\begin{tabular}{|c|c|c|c|c|c|c|}
\hline \multirow{2}{*}{$d / \mathrm{nm}$} & \multirow{2}{*}{$d^{-1} / \mathrm{nm}^{-1}$} & \multicolumn{5}{|c|}{$\ln \left[k /\left(\left(\mathrm{kPa}^{-1}\right)^{1-n} \cdot \min ^{-1}\right)\right]$} \\
\hline & & $473 \mathrm{~K}$ & $493 \mathrm{~K}$ & $513 \mathrm{~K}$ & $533 \mathrm{~K}$ & $553 \mathrm{~K}$ \\
\hline 71.9 & 0.0139 & 12.4 & 22.0 & 27.8 & 30.3 & 34.8 \\
\hline 57.6 & 0.0174 & 18.6 & 25.8 & 29.8 & 33.6 & 38.1 \\
\hline 49.1 & 0.0204 & 20.5 & 30.4 & 33.2 & 34.6 & 43.9 \\
\hline 33.3 & 0.0300 & 26.0 & 34.3 & 41.4 & 46.3 & 59.0 \\
\hline 26.0 & 0.0384 & 27.7 & 43.0 & 47.6 & 53.1 & 65.1 \\
\hline 17.9 & 0.0560 & 44.9 & 55.1 & 61.9 & 66.3 & 77.8 \\
\hline
\end{tabular}

TABLE 3: The reaction orders for different particle diameters at different temperatures.

\begin{tabular}{lccccc}
\hline$d / \mathrm{nm}$ & \multicolumn{3}{c}{ Reaction order $n$} & $533 \mathrm{~K}$ & 2.30 \\
\hline 71.9 & $473 \mathrm{~K}$ & $493 \mathrm{~K}$ & $513 \mathrm{~K}$ & 2.10 & 2.60 \\
57.6 & 1.40 & 1.80 & 2.00 & 2.60 & 2.40 \\
49.1 & 1.40 & 1.60 & 2.30 & 2.30 & 2.90 \\
33.3 & 1.90 & 2.70 & 2.80 & 3.50 & 3.20 \\
26.0 & 2.50 & 3.20 & 3.40 & 3.60 & 3.70 \\
17.9 & 2.90 & 3.50 & 3.60 & 30 \\
\hline
\end{tabular}

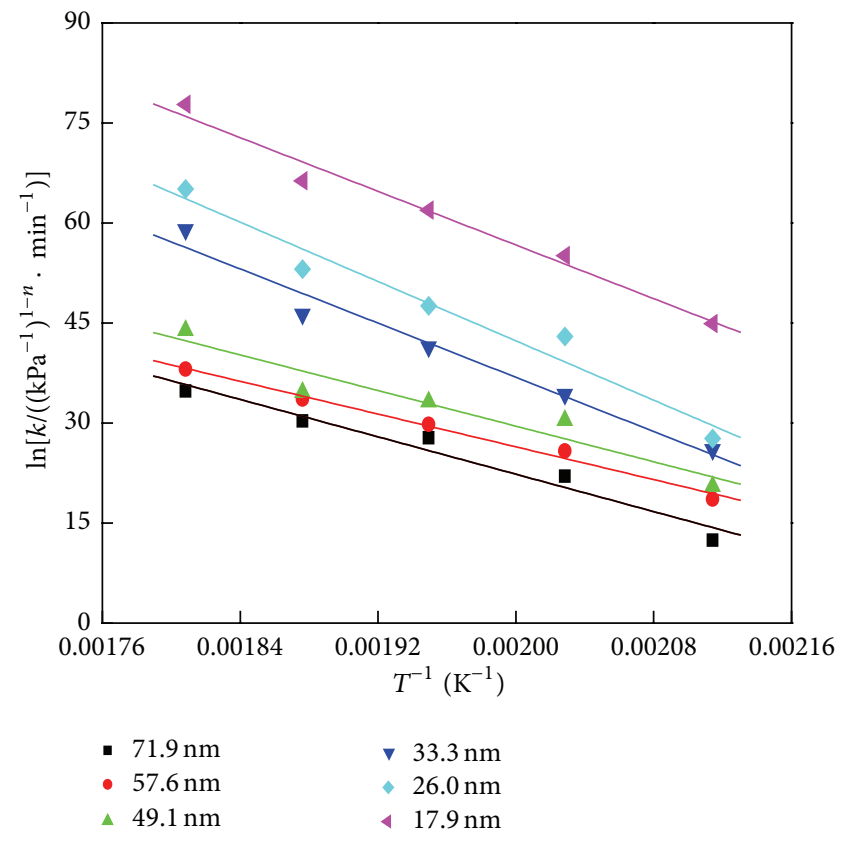

FIGURE 4: The curves of logarithms of rate constants versus reciprocals of temperatures for different particle diameters.

23]. The apparent activation energy is proportional linearly to the reciprocal of particle diameter, which is consistent with the results reported in literatures [15-17, 22]. Based on our previous theoretical analysis $[15,22]$, the theoretical relationship between the apparent activation energy and the reciprocal of particle diameter will be discussed below.

Assume that there is an energy barrier (i.e., transition state) during the reaction between nanoparticle $\mathrm{A}$ and

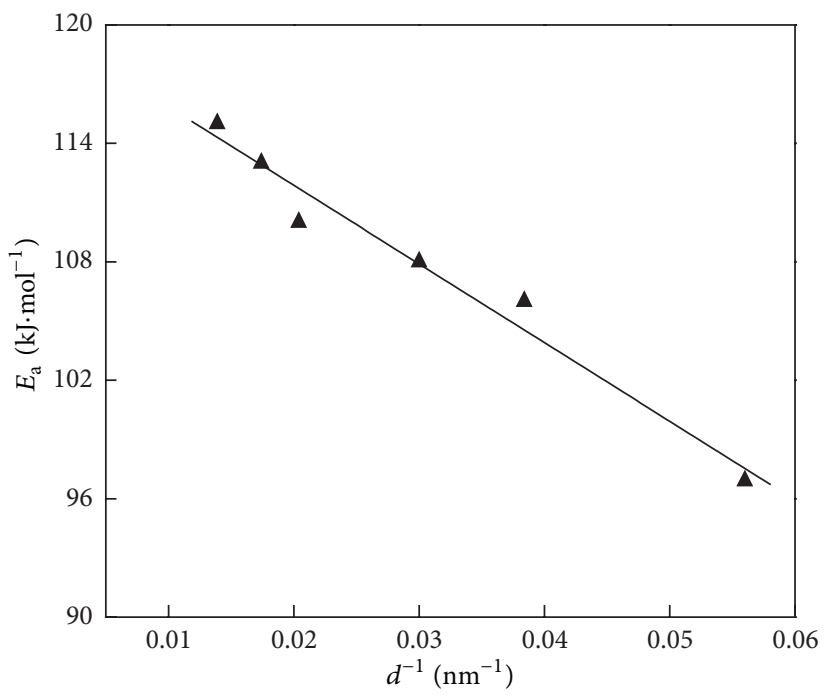

FIGURE 5: The curve of apparent activation energies versus reciprocals of particle diameters.

another reactant B (gas) and the intermediate product corresponding to the transition state is the activated complex $\mathrm{C}^{\ddagger}$ (denoted by ${ }^{\ddagger}$ ). The molar energy barrier $\left(\Delta^{\ddagger} E\right)$ can be calculated by the following formula:

$$
\Delta^{\ddagger} E_{\mathrm{m}}=E_{\mathrm{m}}\left(\mathrm{C}^{\ddagger}\right)-\left(E_{\mathrm{m}}(\mathrm{A})+E_{\mathrm{m}}(\mathrm{B})\right),
$$

where $E_{\mathrm{m}}(\mathrm{A}), E_{\mathrm{m}}(\mathrm{B})$, and $E_{\mathrm{m}}\left(\mathrm{C}^{\ddagger}\right)$ are the molar energy of reactant $A$, reactant $B$, and activated complex $C^{\ddagger}$, respectively.

Assuming that one molar energy of nanoparticles consists of the energy of one molar bulk phase $\left(E_{m}^{\mathrm{b}}(A)\right)$ and the energy 


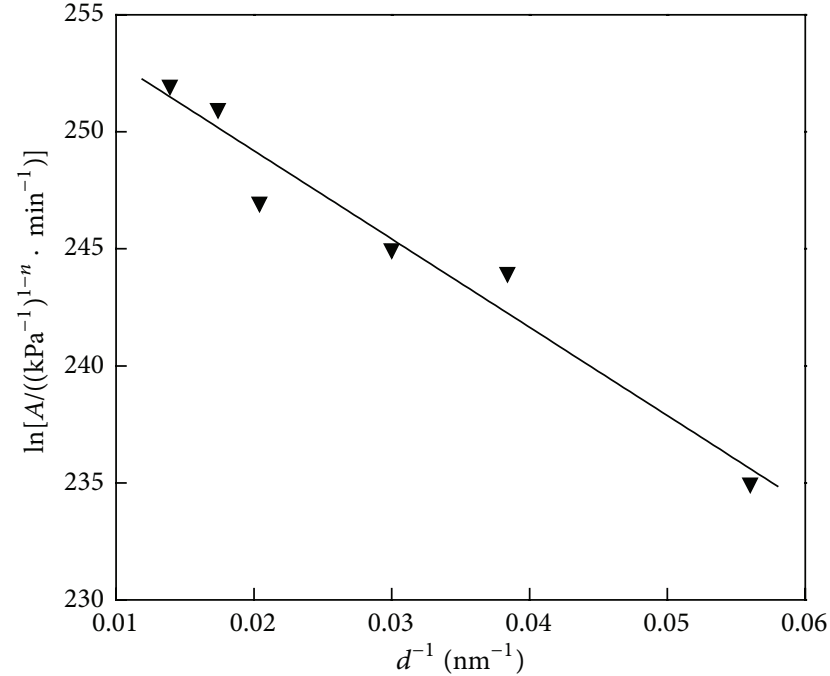

Figure 6: The curve of logarithms of preexponential factors versus reciprocals of particle diameters.

of one molar surface phase $\left(E_{\mathrm{m}}^{\mathrm{s}}(\mathrm{A})\right.$ ), (the superscript $\mathrm{b}$ and $\mathrm{s}$ are used to indicate bulk phase and surface phase, resp.)

$$
E_{\mathrm{m}}(\mathrm{A})=E_{\mathrm{m}}^{\mathrm{b}}(\mathrm{A})+E_{\mathrm{m}}^{\mathrm{s}}(\mathrm{A}) .
$$

Assuming that when nanoparticles act as the reactant, the molar energy of the activated complex $\left(E_{\mathrm{m}}\left(\mathrm{C}^{\ddagger}\right)\right)$ is equal to the molar energy of the activated complex $\left(E_{\mathrm{m}}^{\mathrm{b}}\left(\mathrm{C}^{\ddagger}\right)\right)$ when the same material but bulk particles act as the reactant.

Consider

$$
E_{\mathrm{m}}\left(\mathrm{C}^{\ddagger}\right)=E_{\mathrm{m}}^{\mathrm{b}}\left(\mathrm{C}^{\ddagger}\right) .
$$

Using (7) and (8) into (6), the following equation is obtained:

$$
E_{\mathrm{a}}=E_{\mathrm{a}}^{\mathrm{b}}-E_{\mathrm{m}}^{\mathrm{s}}(\mathrm{A}),
$$

where $E_{\mathrm{a}}^{\mathrm{b}}$ is the apparent activation energy for the corresponding bulk reactant.

Consider

$$
E_{\mathrm{a}}^{\mathrm{b}}=E_{\mathrm{m}}^{\mathrm{b}}\left(\mathrm{C}^{\ddagger}\right)-E_{\mathrm{m}}^{\mathrm{b}}(\mathrm{A})-E_{\mathrm{m}}(\mathrm{B}) .
$$

As shown in (10), the apparent activation energy of nanoparticles as the reactant is lower than the same material but bulk particles as the reactant, the reduce of activation energy roots in the molar surface energy of nanoparticles; that is, the essence of the decrease of the activation energy of nanoparticles is that the larger molar surface energy leads to the increase of the average molar energy of reactants, but the molar energy of intermediate activated complex stays unchanged, causing the activation energy decreases.

For the produced nano-ZnS are spherical particles, the molar surface energy of the particle can be expressed as follows $[16,17]$ :

$$
E_{\mathrm{m}}^{\mathrm{s}}(\mathrm{A})=\frac{6 \sigma V_{\mathrm{m}}}{d}
$$

TABLE 4: The apparent activation energies and the logarithms of preexponential factors for different particle diameters.

\begin{tabular}{lccc}
\hline$d / \mathrm{nm}$ & $d^{-1} / \mathrm{nm}^{-1}$ & $E_{\mathrm{a}} / \mathrm{kJ} \cdot \mathrm{mol}^{-1}$ & $\ln \left[A /\left(\left(\mathrm{kPa}^{-1}\right)^{1-n} \cdot \mathrm{min}^{-1}\right)\right]$ \\
\hline 71.9 & 0.0139 & 115 & 252 \\
57.6 & 0.0174 & 113 & 251 \\
49.1 & 0.0204 & 110 & 247 \\
33.3 & 0.0300 & 108 & 245 \\
26.0 & 0.0384 & 106 & 244 \\
17.9 & 0.0560 & 96.9 & 235 \\
\hline
\end{tabular}

where $\sigma$ is the surface tension, $V_{\mathrm{m}}$ is the molar volume, and $d$ is the diameter of the particles.

Using (11) into (9), the apparent activation energy is given as follows:

$$
E_{\mathrm{a}}=E_{\mathrm{a}}^{\mathrm{b}}-\frac{6 \sigma V_{\mathrm{m}}}{d} .
$$

It is seen from (12) that the apparent activation energy is related to particle size. Only if the radius of the nanoparticles approaches or reaches the order of $10^{-9} \mathrm{~m}$ would the effect become significant [24]. The particles used in this experiment are dozens of nanometers, so the influence of particle size on the surface tension is very small and the surface tension can be seen as a constant. Then the apparent activation energy decreases with the decrease of its diameter and the apparent activation energy exhibits a linear relationship with the reciprocal of the particle diameter. The above theory analysis explains well about the experimental regularity of the influence of particle size on the apparent activation energy. In addition, as shown in the (9), the effect of particle size on the apparent activation energy is exerted through the molar surface energy and the larger molar surface energy, the smaller apparent activation energy.

From Table 4, the curve of logarithms of the preexponential factors versus the reciprocal of the particle diameters are shown as follows.

The results presented in Figure 6 show that the particle size of nano-ZnS has a notable influence on the preexponential factor. The preexponential factor decreases with the decrease of the particle diameter and the regularity is consistent with the results in literatures [15-17], but is contrary to the literature result [25]. By comparison, there are many differences in the particles of the reactants. They used porous microsized coal particles as reactants, but we used nanosized solid particles. The specific surface area of the micropores is much larger than that of the outer surface of the particles. Furthermore, the radius of curvature of outer surface of particles is positive, while that of inner micropore is negative. Maybe the radius of curvature is one of the important effect factors of regularity. The positive or negative of the radius of curvature might lead to the contradiction among the literatures.

In addition, the logarithm of preexponential factor exhibits a linear relationship with the reciprocal of the particle diameter and the regularity is consistent with the results reported in literature [15]. 
According to the transition state theory, if a chemical reaction occurs at a certain temperature, the preexponential factor is proportional to $\exp \left(\Delta^{\ddagger} S_{\mathrm{m}} / R\right)$ [26] and so the equation is derived as follows:

$$
\ln A=\frac{\Delta^{\ddagger} S_{\mathrm{m}}}{R}+\ln \frac{k_{\mathrm{B}} T e^{n}\left(R T / p^{\theta}\right)^{n-1}}{h}=\frac{\Delta^{\ddagger} S_{\mathrm{m}}}{R}+C,
$$

where $\Delta^{\ddagger} S_{\mathrm{m}}$ is molar activation entropy for nanoparticles, $k_{\mathrm{B}}$ is the Boltzmann constant, $h$ is the Planck constant, and $n$ is reaction order.

Consider

$$
\Delta^{\ddagger} S_{\mathrm{m}}=S_{\mathrm{m}}\left(\mathrm{C}^{\ddagger}\right)-S_{\mathrm{m}}(\mathrm{A})-S_{\mathrm{m}}(\mathrm{B}) .
$$

Assuming that the particle size has no effect on the entropy of intermediate complex at transition state, that is, no matter what the reactant is, nanoparticle or bulk substance, the molar entropy of the intermediate complex is the same,

$$
S_{\mathrm{m}}\left(\mathrm{C}^{\ddagger}\right)=S_{\mathrm{m}}^{\mathrm{b}}\left(\mathrm{C}^{\ddagger}\right) \text {. }
$$

Assuming that one molar entropy of nanoparticle $\left(S_{\mathrm{m}}(\mathrm{A})\right)$ consists of the entropy of one molar bulk phase $\left(S_{\mathrm{m}}^{\mathrm{b}}(\mathrm{A})\right)$ and the energy of one molar surface phase $\left(S_{\mathrm{m}}^{\mathrm{s}}(\mathrm{A})\right)$,

$$
S_{\mathrm{m}}(\mathrm{A})=S_{\mathrm{m}}^{\mathrm{b}}(\mathrm{A})+S_{\mathrm{m}}^{\mathrm{s}}(\mathrm{A}) .
$$

From (14), (15), and (16), the following equation is obtained:

$$
\begin{aligned}
\Delta^{\ddagger} S_{\mathrm{m}} & =S_{\mathrm{m}}^{\mathrm{b}}\left(\mathrm{C}^{\ddagger}\right)-S_{\mathrm{m}}^{\mathrm{b}}(\mathrm{A})-S_{\mathrm{m}}^{\mathrm{s}}(\mathrm{A})-S_{\mathrm{m}}(\mathrm{B}) \\
& =\Delta^{\ddagger} S_{\mathrm{m}}^{\mathrm{b}}-S_{\mathrm{m}}^{\mathrm{s}}(\mathrm{A}),
\end{aligned}
$$

where $\Delta^{\ddagger} S_{\mathrm{m}}^{\mathrm{b}}$ is the corresponding molar activation entropy when the reactant is a bulk substance.

Similarly,

$$
\Delta^{\ddagger} G_{\mathrm{m}}=\Delta^{\ddagger} G_{\mathrm{m}}^{\mathrm{b}}-G_{\mathrm{m}}^{\mathrm{s}}(\mathrm{A}),
$$

where $\Delta^{\ddagger} G_{\mathrm{m}}$ is the molar activation Gibbs free energy, $\Delta^{\ddagger} G_{\mathrm{m}}^{\mathrm{b}}$ is the molar activation Gibbs free energy for bulk phase, and $G_{\mathrm{m}}^{\mathrm{s}}(\mathrm{A})$ is the molar surface Gibbs function for nanoparticle A.

For the spherical nanoparticle, the molar surface Gibbs function is

$$
G_{\mathrm{m}}^{\mathrm{s}}(\mathrm{A})=\frac{6 \sigma V_{\mathrm{m}}}{d} .
$$

Using (19) into (18), the molar activation Gibbs free energy can be expressed as follows:

$$
\Delta^{\ddagger} G_{\mathrm{m}}=\Delta^{\ddagger} G_{\mathrm{m}}^{\mathrm{b}}-\frac{6 \sigma V_{\mathrm{m}}}{d} .
$$

Ignoring the influence of temperature on the molar volume of nanoparticles, the following equation is obtained:

$$
\Delta^{\ddagger} S_{\mathrm{m}}=-\left(\frac{\partial \Delta^{\ddagger} G_{\mathrm{m}}}{\partial T}\right)_{T}=\Delta^{\ddagger} S_{\mathrm{m}}^{\mathrm{b}}+\frac{6 V_{\mathrm{m}}}{d}\left(\frac{\partial \sigma}{\partial T}\right)_{p} .
$$

Comparing (17) and (21), the following equation can be obtained:

$$
S_{\mathrm{m}}^{\mathrm{s}}(\mathrm{A})=-\frac{6 V_{\mathrm{m}}}{d}\left(\frac{\partial \sigma}{\partial T}\right)_{p} .
$$

Using (17) or (21) into (13), the following equation is obtained:

$$
\begin{aligned}
\ln A & =\frac{1}{R}\left(\Delta^{\ddagger} S_{\mathrm{m}}^{\mathrm{b}}-S_{\mathrm{m}}^{\mathrm{s}}(\mathrm{A})\right)+C \\
& =\frac{1}{R}\left[\Delta^{\ddagger} S_{\mathrm{m}}^{\mathrm{b}}+\frac{6 V_{\mathrm{m}}}{d}\left(\frac{\partial \sigma}{\partial T}\right)_{p}\right]+C .
\end{aligned}
$$

As shown in (23), for the common materials, the $(\partial \sigma / \partial T)_{p}<0$. As the discussion above, in this experiment, the influence of particle size on the surface tension can be ignored. Therefore, the preexponential factor decreases with the decreasing particle size of reactant and $\ln A$ exhibits a linear relationship with the reciprocal of the particle diameter. The above theory analysis explains well about the experimental regularity of the influence of particle size on the preexponential factor. Additionally, the effect of particle size on the preexponential factor is through its molar surface entropy and the smaller the nanoparticle size, the larger the molar surface entropy and the smaller the preexponential factor.

The influence regularity of reactant size on the preexponential factor and apparent activation energy can be used to explain the influent regularity of reactant size on its rate constant. By (12), (23), and the Arrhenius equation, the following equations are obtained:

$$
\begin{aligned}
& \ln k=\frac{1}{R T}\left[E_{\mathrm{m}}^{\mathrm{s}}(\mathrm{A})-T S_{\mathrm{m}}^{\mathrm{s}}(\mathrm{A})\right]+C_{1}, \\
& \ln k=\frac{6 \sigma V_{\mathrm{m}}}{R T d}\left[1+\frac{T}{\sigma}\left(\frac{\partial \sigma}{\partial T}\right)_{p}\right]+C_{1},
\end{aligned}
$$

where $C_{1}$ is a certain constant, which is related to temperature only. Namely,

$$
C_{1}=\frac{\Delta^{\ddagger} S_{\mathrm{m}}^{\mathrm{b}}}{R}-\frac{E_{\mathrm{a}}^{\mathrm{b}}}{R T}+C .
$$

The surface enthalpy $H^{\mathrm{s}}$ is

$$
H^{\mathrm{s}}=G^{\mathrm{s}}+T S^{\mathrm{s}} \text {. }
$$

Often, and as a good approximation, surface enthalpy $H^{\mathrm{s}}$ and surface energy $E^{\mathrm{s}}$ are not distinguished, so (27) can be seen in the form as follows [27]:

$$
E^{s}=G^{s}+T S^{s}
$$

Equation (24) can be simplified as follows:

$$
\ln k=\frac{G_{\mathrm{m}}^{\mathrm{s}}}{R T}+C_{1}=\frac{6 \sigma V_{\mathrm{m}}}{R T d}+C_{1} .
$$

Just as the discussion above, the surface tension can be seen as constant in this experiment. As shown in (29), the 
rate constant increases with the decrease of nanoparticles and the logarithm of rate constant exhibits a linear relationship with the reciprocal of the particle diameter. The above theory analysis explains well about the experimental regularity of the influence of particle size on the rate constant.

As shown in (24), the logarithm of rate constant of nanoreactant is related to its molar surface energy and molar surface entropy; but molar surface energy and molar surface entropy have the opposite effect on the rate constant, because molar surface energy of nanoreactant makes rate constant larger, while molar surface entropy makes rate constant smaller. Therefore, the particle size effect on the rate constant is the result of the combined action of molar surface energy and molar surface entropy. In the process of the reaction of nanoparticles, the molar surface energy of nanoparticles disappears, which causes the decrease of system energy and makes it easier for the reaction. At the same time, the molar surface entropy of nanoparticles also disappears, which causes the decrease of system entropy and makes it more difficult for the reaction. As for the solid nanoparticles, the molar surface entropy is so small that the effect of molar surface energy on the rate constant is dominant. Therefore, the smaller the particle size, the larger the rate constant.

\section{Conclusions}

Through experimental study and theoretical analysis, it can be concluded that the particle size of nano- $\mathrm{ZnS}$ has a significant effect on the kinetic parameters of oxidation reaction. The results show that the particle size of nano$\mathrm{ZnS}$ can observably affect the oxidation reaction kinetics. The reaction rate constant and the reaction order increase, while the apparent activation energy and the preexponential factor decrease with the decreasing particle diameter. Moreover, the logarithm of rate constant, the apparent activation energy, and the logarithm of preexponential factor exhibit linear relations with the reciprocal of the particle diameter, respectively. The essence of particle size effect on oxidation reaction kinetics is that the rate constant is influenced by the combined effect of molar surface energy and molar surface entropy, the reaction order by the molar surface area, the apparent activation energy by the molar surface energy, and the preexponential factor by the molar surface entropy. The influence regularities and essence can provide theoretical guidance to solve the oxidation problems involved in the process of preparation and application of nanomaterials.

\section{Conflict of Interests}

The authors declare that there is no conflict of interests regarding the publication of this paper.

\section{Acknowledgment}

The authors are so grateful for the support from the National Natural Scientific Fund (no. 21373147).

\section{References}

[1] K. Vasundhara, S. N. Achary, S. K. Deshpande, P. D. Babu, S. S. Meena, and A. K. Tyagi, "Size dependent magnetic and dielectric properties of nano $\mathrm{CoFe}_{2} \mathrm{O}_{4}$ prepared by a salt assisted gel-combustion method," Journal of Applied Physics, vol. 113, no. 19, Article ID 194101, 9 pages, 2013.

[2] O. V. Molodtsova, I. M. Aristova, S. V. Babenkov, O. V. Vilkov, and V. Yu. Aristov, "Morphology and properties of a hybrid organic-inorganic system: Al nanoparticles embedded into CuPc thin film," Journal of Applied Physics, vol. 115, Article ID 164310, 2014.

[3] M. M. Vijatović, B. D. Stojanović, J. D. Bobić, T. Ramoska, and P. Bowen, "Properties of lanthanum doped $\mathrm{BaTiO}_{3}$ produced from nanopowders," Ceramics International, vol. 36, no. 6, pp. 18171824,2010

[4] C. S. Ciobanu, F. Massuyeau, L. V. Constantin, and D. Predoi, "Structural and physical properties of antibacterial Ag-doped nano-hydroxyapatite synthesized at $100^{\circ} \mathrm{C}$," Nanoscale Research Letters, vol. 6, article 613, 2011.

[5] Z. Dehghani, S. Nazerdeylami, E. Saievar-Iranizad, and M. H. Majles Ara, "Synthesis and investigation of nonlinear optical properties of semiconductor ZnS nanoparticles," Journal of Physics and Chemistry of Solids, vol. 72, no. 9, pp. 1008-1010, 2011.

[6] A. K. Kole and P. Kumbhakar, "Effect of manganese doping on the photoluminescence characteristics of chemically synthesized zinc sulfide nanoparticles," Applied Nanoscience, vol. 2, pp. 15-23, 2012.

[7] X. F. Wang, H. T. Huang, B. Liang, Z. Liu, D. Chen, and G. Z. Shen, "ZnS nanostructures: synthesis, properties, and applications," Critical Reviews in Solid State and Materials Sciences, vol. 38, no. 1, pp. 57-90, 2013.

[8] J. Tolia, Z. V. P. Murthy, and M. Chakraborty, "Application of mechanochemically synthesised $\mathrm{ZnS}$ nanoaprticles in photocatalytic oxidation of phenol," Research Journal of Chemistry and Environment, vol. 15, no. 2, pp. 223-228, 2011.

[9] D. A. Reddy, G. Murali, A. Divya, R. P. Vijayalakshmi, and B. K. Reddy, "Investigations on $\mathrm{ZnS}$ nanoparticles based on synthesis temperature for optoelectronic device applications," Journal of Optoelectronics and Advanced Materials, vol. 12, no. 11, pp. 21852189, 2010

[10] K. V. Anand, R. Mohan, R. M. Kumar, M. K. Chinnu, and R. Jayavel, "Structural and optical properties of high-purity cubic phase $\mathrm{ZnS}$ nanoparticles prepared by thermal decomposition route for optoelectronic applications," Proceedings of the Indian National Science Academy, vol. 79, pp. 395-399, 2013.

[11] K. Park, D. Lee, A. Rai, D. Mukherjee, and M. R. Zachariah, "Size-resolved kinetic measurements of aluminum nanoparticle oxidation with single particle mass spectrometry," Journal of Physical Chemistry B, vol. 109, no. 15, pp. 7290-7299, 2005.

[12] T. X. Phuoc and R. Chen, "Modeling the effect of particle size on the activation energy and ignition temperature of metallic nanoparticles," Combustion and Flame, vol. 159, no. 1, pp. 416419, 2012.

[13] L. Zhou, A. Rai, N. Piekiel, X. Ma, and M. R. Zachariah, "Ionmobility spectrometry of nickel nanoparticle oxidation kinetics: application to energetic materials," Journal of Physical Chemistry C, vol. 112, no. 42, pp. 16209-16218, 2008.

[14] K. J. Higgins, H. Jung, D. B. Kittelson, J. T. Roberts, and M. R. Zachariah, "Size-selected nanoparticle chemistry: kinetics of 
soot oxidation," Journal of Physical Chemistry A, vol. 106, no. 1, pp. 96-103, 2002.

[15] Y. Xue, X. Wang, and Z. Cui, “The effects of particle size on the kinetic parameters in the reaction of nano-NiO with sodium bisulfate solution," Progress in Reaction Kinetics and Mechanism, vol. 36, no. 4, pp. 329-341, 2011.

[16] Y. Xue, J. Du, P. Wang, and Z. Wang, "Effect of particle size on kinetic parameters of the heterogeneous reactions," Acta Physico-Chimica Sinica, vol. 21, no. 7, pp. 758-762, 2005.

[17] Y. Q. Xue, H. Zhao, and J. P. Du, "Effect of particle size on kinetic parameters of heterogeneous reactions," Wuji Huaxue Xuebao, vol. 22, no. 11, pp. 1952-1956, 2006.

[18] Z. Y. Li, K. Yu, Y. Gao, J. Liu, D. Jin, and Y. C. Zhai, "Effect of particle size on hydrogen reduction reaction kinetics parameters of $\mathrm{Cu}_{2} \mathrm{O}$ powders," Materials Science Forum, vol. 694, pp. 769-772, 2011.

[19] J. M. Criado and A. Ortega, "A study of the influence of particle size on the thermal decomposition of $\mathrm{CaCO}_{3}$ by means of constant rate thermal analysis," Thermochimica Acta, vol. 195, pp. 163-167, 1992.

[20] K. Hoang, A. Janotti, and C. G. van de Walle, "The particlesize dependence of the activation energy for decomposition of lithium amide," Angewandte Chemie-International Edition, vol. 50, no. 43, pp. 10170-10173, 2011.

[21] V. M. Abdul Mujeeb, K. Muraleedharan, M. P. Kannan, and T. Ganga Devi, "The effect of particle size on the thermal decomposition kinetics of potassium bromate," Journal of Thermal Analysis and Calorimetry, vol. 108, no. 3, pp. 1171-1182, 2012.

[22] Z. Cui, Y. Xue, L. Xiao, and T. Wang, "Effect of particle size on activation energy for thermal decomposition of nano- $\mathrm{CaCO}_{3}$," Journal of Computational and Theoretical Nanoscience, vol. 10, no. 3, pp. 569-572, 2013.

[23] J. Pang, P. Guo, P. Zhao, C. Cao, and D. Zhang, "Influence of size of hematite powder on its reduction kinetics by $\mathrm{H} 2$ at low temperature," Journal of Iron and Steel Research International, vol. 16, no. 5, pp. 07-11, 2009.

[24] Y. Q. Xue, X. C. Yang, Z. Cui, and W. P. Lai, "The effect of microdroplet size on the surface tension and tolman length," Journal of Physical Chemistry B, vol. 115, no. 1, pp. 109-112, 2011.

[25] B. Coda and L. Tognotti, "The prediction of char combustion kinetics at high temperature," Experimental Thermal and Fluid Science, vol. 21, no. 1-3, pp. 79-86, 2000.

[26] P. Atkins and J. de Paula, Atkins' Physical Chemistry, Higher Education Press, 2006.

[27] A. W. Adamson and A. P. Gast, Physical Chemistry of Surfaces, Wiley-Interscience, 1997. 

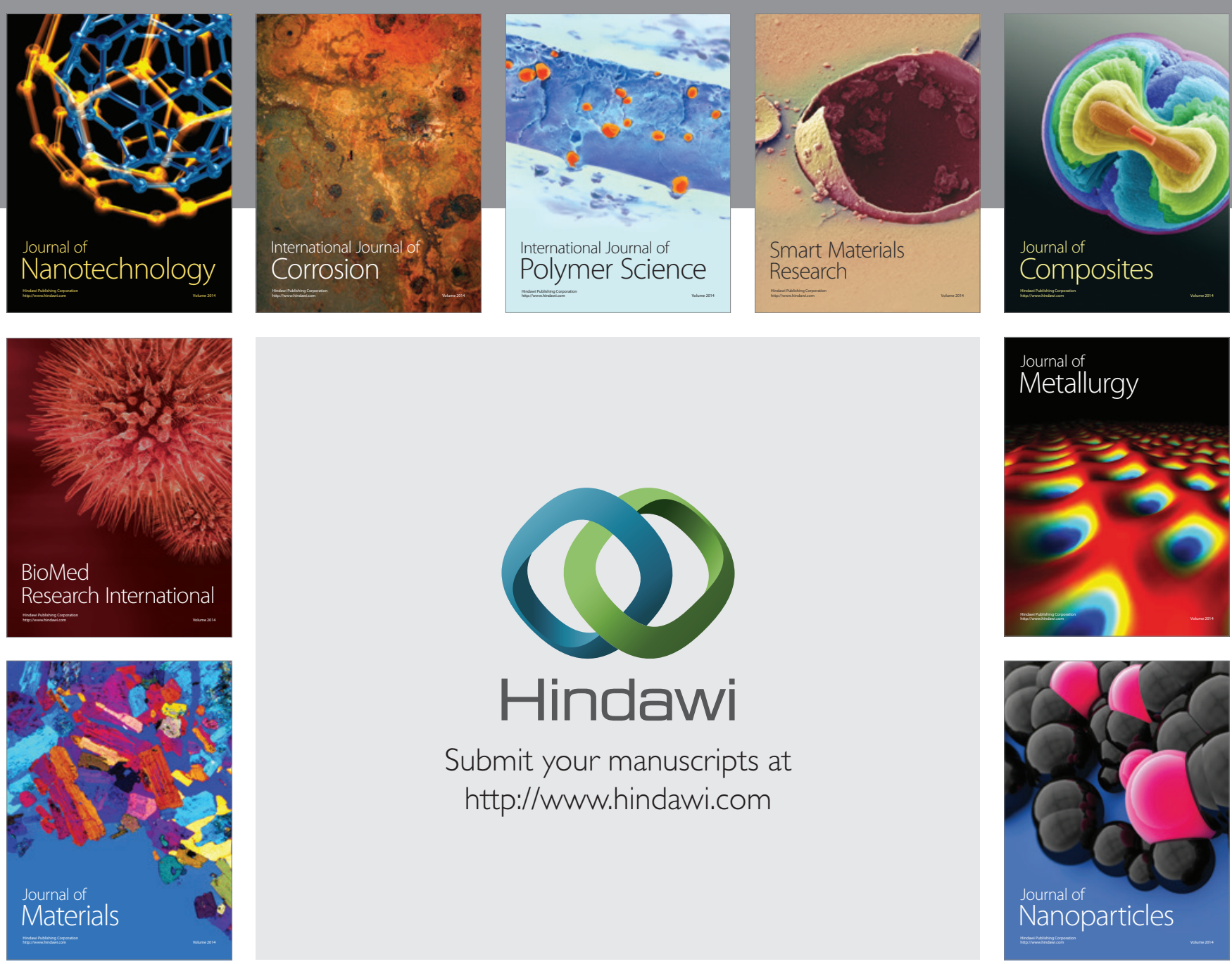

Submit your manuscripts at http://www.hindawi.com
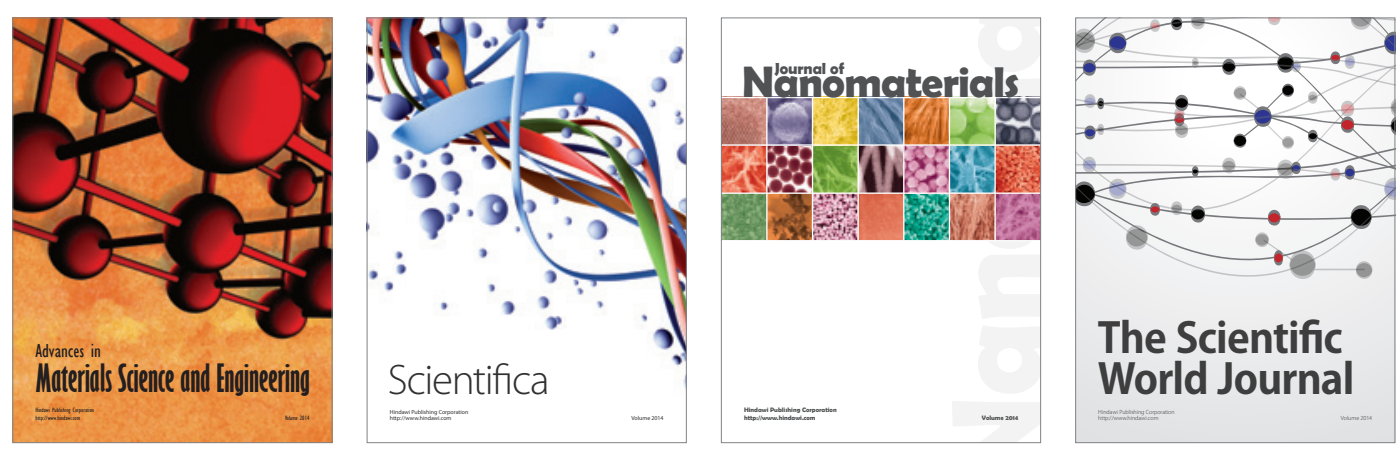

\section{The Scientific World Journal}
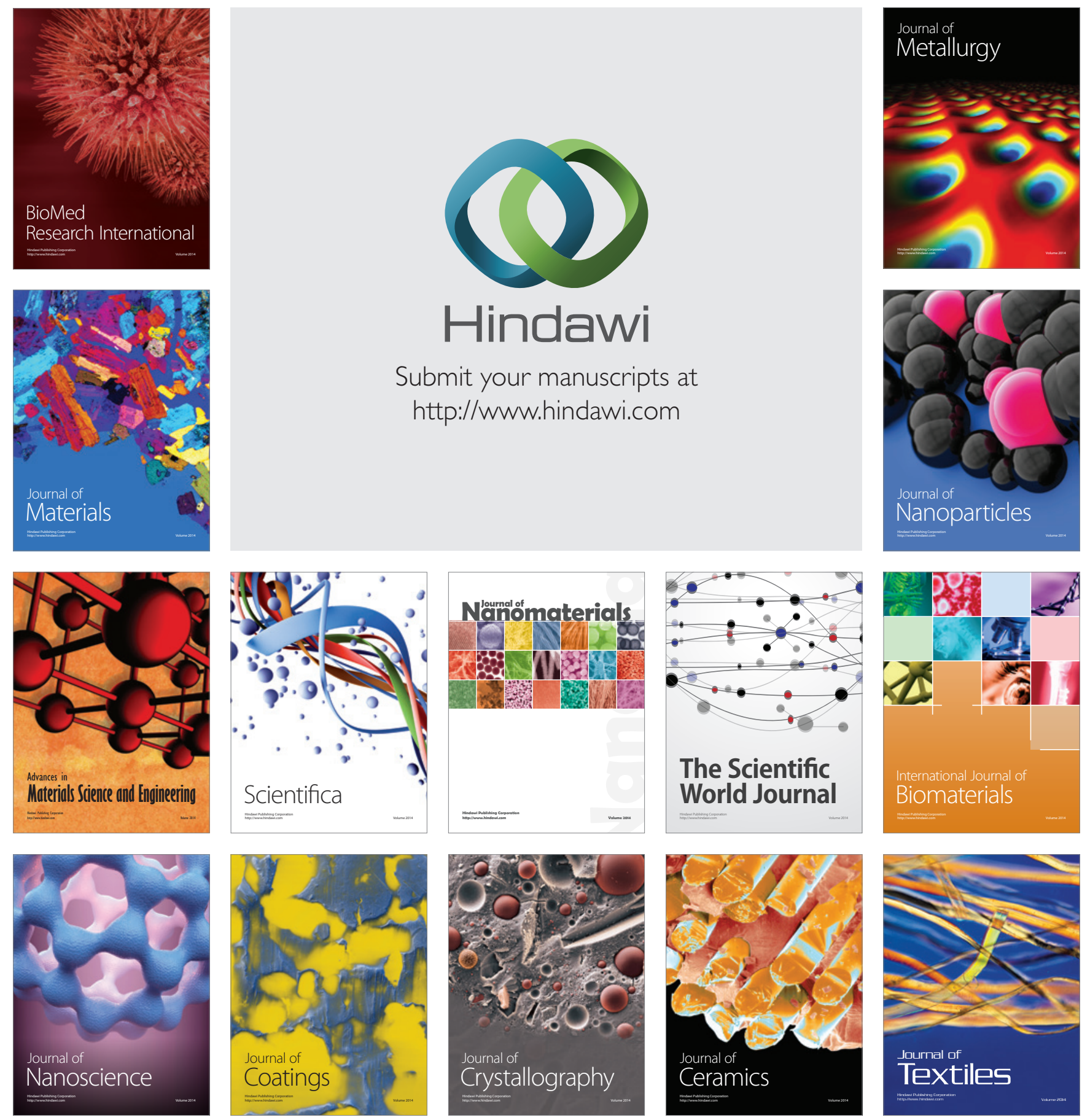